\title{
EDITORIAL
}

\section{Shifting Paradigms, Practices and Policies in Media Communication}

The unprecedented changes in the ways we create process, distribute and consume content today are not only challenging the media industry but the society we live in and the institutions that govern us. Fuelled by the developments in technology, innovation and creativity, the media situation world over is opening up immense possibilities of communicating, connecting and engaging. Yet, the advances in mass, social and digital media are posing unparalleled challenges, fears and risks.

The number of mobile phones will reach over 5 billion by the end of the year 2019 while the number of internet users has already crossed four billion mark and active users of social media are over 3 billion now. In the first quarter of the year 2019, there were 2.38 billion monthly active users of Facebook, 1.5 billion active users of WhatsApp in 180 different countries of the world.

This mammoth growth in mobile devices, social media, cheap Wi-Fi and broadband connectivity along with the ease of using mobile devices has led to phenomenal growth in the creation and distribution of content we have never seen before. There is no doubt, that we are witnessing a democratization of media and communication processes, leading to the empowerment of subaltern and dispossessed groups and individuals through the issues of knowledge gap still remain critical. However, the slow but certain replacement of the conventional media by the social, digital and mobile media is increasingly leading to the lack of editorial control to separate facts from fictions, distinguish news from views, and to check the spread of rumors and hearsay.

With a smart device in hand and Wi-Fi connection, the technology has enabled every individual to become a potential broadcaster. The social media platforms which defy time and space, offer unmatched access to post, forward and recycle content (text, images, video) at electrifying speed and fidelity. In this infinite media-scape, there is no legislation to safeguard the principles of ethical and professional practice. No wonder, we are dealing today with an alarming increase in the spread of fake news, creation of alternative truths, running trolling and propaganda machines.

This all is happening when conventional media platforms like newspapers, Television, and radio networks are losing readers and audiences. A look at the newspaper in the USA shows that 516 rural newspapers shut down or merged from 2004 to 2018 while in Cities $\backslash, 1,294$ newspapers stopped publication in this period. There was loss of 1 , 810 papers. Similarly in the UK in 2017 alone, 40 local newspapers were closed. The story is not very different in other parts of the world with a few exceptions.

While these developments are accelerating at a nauseating speed, the media schools and the scholarship is watching in dismay. Our curriculum is outdated, our approach is archaic and our actions are reactive. A holistic approach that engages various disciplines and perspectives is critical in responding positively to the change. Media scholars and academics have to be proactive before they themselves become redundant.

Against this backdrop the International Conference on Current Practices and Future Trends in Media Communication (CPFTMC2019), adopting a multi-perspective approach to engage Liberal Arts, Humanities, Social Sciences, Business Studies \& Economics, Technology and Data Sciences, provides a dynamic platform for a holistic understanding of the media discourse that is shaping up at the dawn of the 4th Industrial Revolution. With the objective of promoting research, the conference brings together renowned academics, media practitioners and scholars developing responses and creating strategies to deal with the overwhelming changes in media communication.

\section{Dr. Fazal Malik}

Dean Humanities, Arts and Applied Sciences, Amity University Dubai

\section{Dr. Sumit Narula}

Director, Amity School of Communication, Amity University Gwalior 